\title{
miRNA-199b-3p suppresses growth and progression of ovarian cancer via the CHK1/E-cadherin/EMT signaling pathway by targeting ZEB1
}

\author{
LIQUN WEI ${ }^{1}$, YUANQI HE ${ }^{1}$, SHUHONG BI ${ }^{1}$, XIAOXIAO LI ${ }^{1}$, JIANZHONG ZHANG ${ }^{1}$ and SHIHONG ZHANG ${ }^{1,2}$ \\ ${ }^{1}$ Department of Gynecology and Obstetrics, Weihai Municipal Hospital, Shandong University, Weihai, Shandong 264200; \\ ${ }^{2}$ Department of Gynecology and Obstetrics, Affiliated Hospital of Beihua University, Jilin, Jilin 132001, P.R. China
}

Received January 14, 2019; Accepted April 1, 2020

DOI: $10.3892 / o r .2020 .7895$

\begin{abstract}
Ovarian cancer is one of the most common gynecological malignancies and its pathogenesis and progression are regulated by multiple genes. MicroRNAs (miRNAs) are endogenous non-coding RNAs that regulate body function by altering post-transcriptional gene expression. Previous studies have suggested that miRNAs are closely associated with the pathogenesis and progression of several malignancies, including breast cancer, hepatocellular carcinoma and glioma, among others. Therefore, miRNAs are promising novel targets for the diagnosis, treatment and determination of prognostic factors in patients with ovarian cancer. In the present study, the role of miRNA-133b-3p in ovarian cancer progression and its possible mechanism of action were investigated. The results demonstrated that the expression of miRNA-199b-3p and zinc finger E-box binding homeobox (ZEB)1 were increased in patients with ovarian cancer. The overall survival (OS) and disease-free survival (DFS) of patients with ovarian cancer and high miRNA-199b-3p expression were prolonged compared with those of patients with low miRNA-199b-3p expression. Additionally, the OS and DFS of patients with ovarian cancer and low ZEB1 expression were longer compared with those of patients with high ZEB1 expression. Furthermore, miRNA-199b-3p overexpression reduced cell proliferation and promoted apoptosis in an in vitro model of ovarian cancer. miRNA-199b-3p overexpression also suppressed ZEB1 and checkpoint kinase 1 expression and induced E-cadherin expression and epithelial-to-mesenchymal transition in this model. Furthermore, the effects of miRNA-199b-3p-mediated apoptosis and migration were attenuated by ZEB1 and E-cadherin,
\end{abstract}

Correspondence to: Dr Shihong Zhang, Department of Gynecology and Obstetrics, Weihai Municipal Hospital, Shandong University, 70 Heping Road, Weihai, Shandong 264200, P.R. China E-mail: sy932545@163.com

Key words: microRNA-199b-3p, ovarian cancer, zinc finger E-box binding homeobox 1, E-cadherin, epithelial-to-mesenchymal transition respectively. The results of the present study indicated that miRNA-199b-3p suppressed ovarian cancer progression by targeting ZEB1, which may represent a promising therapeutic target for ovarian cancer.

\section{Introduction}

Ovarian cancer is one of the most common malignant tumors and poses a major threat to the health of women worldwide (1). Patients with ovarian cancer do not usually exhibit early symptoms and there is a lack of effective screening and diagnostic methods $(1,2)$. Therefore, $\sim 70 \%$ of patients with ovarian cancer are diagnosed at an advanced stage (III-IV), after invasion and metastasis have occurred. Furthermore, ovarian cancer is associated with treatment-related complications and poor prognosis (2).

MicroRNAs (miRNA or miRs) are important regulatory factors that regulate gene expression, cell proliferation and differentiation, tumorigenesis and tumor progression (3). miRNAs exert their affects via base complementary pairing with target gene mRNA, degrading corresponding mRNA or suppressing mRNA translation (4). Recent research has indicated that certain miRNAs are abnormally expressed in ovarian cancer and are involved in tumor pathogenesis, development, metastasis and resistance to treatment (4). The association between miRNAs and ovarian cancer has been extensively investigated, and miRNAs have become a focus of interest in the diagnosis and treatment of ovarian cancer $(3,4)$.

Epithelial-to-mesenchymal transition (EMT) is an important event during invasion and metastasis of ovarian cancer cells and involves multiple signaling pathways and complex molecular mechanisms (5). EMT-related proteins include interleukin-2-inducible T-cell kinase and T-cell-specific kinase (6).

Members of the zinc finger E-box binding homeobox (ZEB) family are important transcription factors that induce EMT (6). ZEB proteins directly or indirectly suppress the expression of adhesion proteins, such as epithelial (E)-cadherin, at the transcriptional level (6) to promote EMT (7). Research into the role of the ZEB family in the EMT of epithelial ovarian cancer cells may provide novel therapeutic targets for slowing ovarian cancer invasion and metastasis (7). 
Ovarian cancer is one of the most common tumors of the female reproductive system (8) and is associated with poor prognosis. EMT is a biological process during which epithelial cells acquire a mesenchymal phenotype through specific pathways. Multiple tumor microenvironment cytokines, including epidermal growth factor, endothelin 1 and bone morphogenetic protein, are involved in EMT during the pathogenesis and progression of ovarian cancer (8) and regulate related signaling pathways to promote cancer development and metastasis (9). Additionally, EMT is associated with chemoresistance in ovarian cancer (9).

One of the hallmarks of EMT is the reduced expression of cell adhesion molecules, including E-cadherin (10). E-cadherin belongs to the cadherin family and its lowered expression is closely associated with tumor invasion and dedifferentiation. It was previously indicated that abnormal E-cadherin expression is closely associated with the pathogenesis and development of ovarian cancer (10), and research into the regulation of E-cadherin expression in ovarian cancer has become a focus of interest.

Zheng et al (11) reported that miR-199b-5p inhibits triple-negative breast cancer cell proliferation, migration and invasion. Koshizuka et al (12) demonstrated that the miR-199 family inhibits cancer cell migration and invasion in head and neck cancer (12). In the present study, the role of miRNA-199b-3p in ovarian cancer progression and its possible mechanism of action was investigated.

\section{Materials and methods}

Patients and samples. Patients with ovarian cancer (aged 57-64 years) and healthy volunteers (controls; aged 55-60 years) were recruited from Weihai Municipal Hospital between July and December 2014. Serum samples were centrifuged at $1,000 \mathrm{x} \mathrm{g}$ for $10 \mathrm{~min}$ at $4^{\circ} \mathrm{C}$ and stored at $-80^{\circ} \mathrm{C}$. The current study protocol was approved by the Medical Ethics Committee of Weihai Municipal Hospital. Written informed consent was obtained from all participants.

The inclusion criteria were as follows: Ovarian cancer was confirmed by pathological examination, all cases of ovarian cancer were non-metastatic and none of the patients had received chemoradiotherapy or radiotherapy. The exclusion criteria were as follows: Patients with metastatic tumours and/or those who had received prior chemoradiotherapy or radiotherapy. Overall survival (OS) and disease-free survival (DFS) were determined by follow-up via telephone communication.

Reverse transcription quantitative PCR (RT-qPCR) analysis. Microarray experiments were performed at Genminix Informatics, Co. Ltd. Gene expression profiles were analyzed with the Human Exon 1.0 ST GeneChip (Affymetrix; Thermo Fisher Scientific, Inc.).

Total RNA was isolated from tissue samples using TRIzol ${ }^{\circledR}$ reagent (Thermo Fisher Scientific, Inc.) according to the manufacturer's protocol. cDNA was synthesized using Moloney murine leukemia virus reverse transcriptase (Promega Corporation). qPCR was then performed using SYBR $^{\circledR}$ Premix Ex Taq ${ }^{\mathrm{TM}}$, according to the manufacturer's protocol (Takara Biotechnology Co., Ltd.). The primers were as follows: miRNA-199b-3p: sense, 5'-CCAGAGGACACC TCCACTCC-3-3' and antisense, 5'-GGGCTGGGTTAGACC CTCGG 3'; and U6: sense, 5'-GCTTCGGCAGCACATATA CTAAAAT-3' and antisense, 5'-CGCTTCACGAATTTGCGT GTCAT-3'. The thermocycling conditions were as follows: $95^{\circ} \mathrm{C}$ for $15 \mathrm{~min}$, followed by 40 cycles at $95^{\circ} \mathrm{C}$ for $2 \mathrm{sec}, 60^{\circ} \mathrm{C}$ for $20 \mathrm{sec}$ and $72^{\circ} \mathrm{C}$ for $20 \mathrm{sec}$. Gene expression was quantified using the $2^{-\Delta \Delta \mathrm{Cq}}$ method (13).

Microarray experiments. High miRNA-199b-3p expression in patients with ovarian cancer was considered as $0.5-1$-fold higher compared with its expression in controls. Low miRNA-199b-3p expression in patients with ovarian cancer was considered as $<0.5$ of its expression in controls. High ZEB1 expression in patients with ovarian cancer was $\geq 2$-fold higher compared with its expression in controls, and low ZEB1 expression was considered as 1-2-fold lower compared with its expression in controls. The correlation between ZEB1 and miRNA-199b-3p expression was analyzed using Pearson's correlation test.

Cell culture and transfection. OVCAR-3 cells were purchased from Shanghai Cell Bank, Chinese Academy of Sciences, and were cultured in RPMI-1640 medium (Thermo Fisher Scientific, Inc.) supplemented with 10\% FBS (Thermo Fisher Scientific, Inc.) and incubated with $5 \% \mathrm{CO}_{2}$ at $37^{\circ} \mathrm{C}$.

Plasmids for ZEB1 (50 ng, 5'-TTCTCCTTCACTTATGAA GC-3' and 5'-AGTCAAGCAAGCAGCTTAGGACAAAAA GTA-3'), E-cadherin (50 ng, 5'-GAGTATGTCCACCGTGTC CAGCGAA-3' and 5'-TTTGTTGTTTGTTGTGTAAATGCA A-3'), miRNA-199b-3p (50 ng, 5'-GCCACCAGTGTTCAG ACTACC-3' and 5'-TAGTCTGCACATTGGTTAGGC-3'), and negative mimics (50 ng, 5'-TTCTCCGAACGTGTCACGT-3' and 5'-TTCTCTAGAACGTGTCAT-3') were purchased from Sangon Biotech Co., Ltd. and were transfected into OVCAR-3 cells using Lipofectamine ${ }^{\mathrm{TM}} 2000$ (Invitrogen; Thermo Fisher Scientific, Inc.).

Dual-luciferase reporter assay. Human ZEB1 3'-UTR genes were cloned into pGL3 luciferase reporter plasmids to construct pGL3-ZEB1 vectors. The aforementioned plasmids were co-transfected with pGL3-ZEB1 vectors using Lipofectamine $^{\mathrm{TM}} 2000$ reagent (Thermo Fisher Scientific, Inc.). Dual-luciferase reporter assays (Promega Corporation) were performed $48 \mathrm{~h}$ after transfection using Dual-luciferase reporter kit (Promega Corporation). Renilla luciferase activity was used to normalize data.

Cell proliferation assay. After $48 \mathrm{~h}$ of transfection, OVCAR-3 cells $\left(1 \times 10^{3}\right.$ cells/well in 96 -well plates) were incubated with $20 \mu \mathrm{l}$ MTT reagent $(5 \mathrm{~g} / \mathrm{l})$ for $4 \mathrm{~h}$ at $37^{\circ} \mathrm{C}$. DMSO $(150 \mu \mathrm{l} /$ well $)$ was then added to OVCAR-3 cells for $20 \mathrm{~min}$ at $37^{\circ} \mathrm{C}$. Optical density (OD) was measured at $490 \mathrm{~nm}$ using a microplate reader (AD-340; Beckman Coulter, Inc.).

Transwell assay. The Transwell assay was performed using 24-well Transwell chambers (Corning Inc.). After $48 \mathrm{~h}$ of transfection, OVCAR-3 cells $\left(1 \times 10^{5}\right.$ cells/well) were seeded into the upper chamber and $500 \mu 1$ DMEM with $10 \%$ FBS were added to the lower chamber to act as a chemoattractant. Cells 
migrating to the lower surface of the filter were fixed with $4 \%$ paraformaldehyde at room temperature for $15 \mathrm{~min}$. Following incubation for $48 \mathrm{~h}$, the cells were stained with $0.1 \%$ crystal violet solution at room temperature for $5 \mathrm{~min}$ and observed using an Olympus BX51 microscope (Olympus Corporation) at a magnification of $\mathrm{x} 40$.

Wound healing assay. After $48 \mathrm{~h}$ of transfection, OVCAR-3 cells $\left(1 \times 10^{5}\right.$ cells/well) were cultured in 6-well plates without FBS at $37^{\circ} \mathrm{C}$ and a linear scratch was created in the center of the well using a 100- $\mu 1$ micropipette tip. Images were captured at 0 and $24 \mathrm{~h}$ of incubation with an Olympus BX51 microscope (Olympus Corporation) at a magnification of $\mathrm{x} 40$.

Flow cytometric analysis of apoptosis using FITC. After $48 \mathrm{~h}$ of transfection, OVCAR-3 cells $\left(1 \times 10^{6}\right.$ cells/well $)$ were washed with PBS for 10 min and fixed with $4 \%$ paraformaldehyde for $15 \mathrm{~min}$ at room temperature. Cells were stained using an Annexin-V/propidium iodide assay (BD Biosciences) according to the manufacturer's protocol for $15 \mathrm{~min}$ at room temperature in the dark. Apoptosis rate was determined using a BD Accuri ${ }^{\mathrm{TM}}$ C6 flow cytometer (BD Biosciences) and analyzed by FlowJo software (version 7.6.1; FlowJo LLC).

Western blotting. Total protein was extracted using RIPA lysis buffer (Beyotime Institute of Biotechnology) and protein concentration was quantified using a BCA Protein Assay kit, according to the manufacturer's protocol (Thermo Fisher Scientific, Inc.). Equal amounts of protein (50 $\mu \mathrm{g} / \mathrm{lane})$ were separated by SDS-PAGE on $10 \%$ gels and then transferred onto PVDF membranes (Bio-Rad Laboratories, Inc.). The membranes were blocked with $5 \%$ non-fat milk with Tris-buffered saline with $0.1 \%$ Tween-20 for $1 \mathrm{~h}$ at $37^{\circ} \mathrm{C}$ and probed with antibodies against ZEB1 (cat. no. sc-81428; 1:500 dilution; Santa Cruz Biotechnology, Inc.), checkpoint kinase 1 (CHK1; cat. no. sc-377231; 1:500 dilution; Santa Cruz Biotechnology, Inc.), E-cadherin (cat. no. sc-71007; 1:500 dilution; Santa Cruz Biotechnology, Inc.), EMT (sc-23902; 1:500 dilution; Santa Cruz Biotechnology, Inc.) and GAPDH (cat. no. sc-69778; 1:5,000 dilution; Santa Cruz Biotechnology, Inc.) at $4^{\circ} \mathrm{C}$ overnight. The membranes were then incubated with goat anti-rabbit horseradish peroxidase-conjugated IgG (cat. no. sc-2004; 1:5,000 dilution; Santa Cruz Biotechnology, Inc.) at $37^{\circ} \mathrm{C}$ for $1 \mathrm{~h}$ and visualized with an enhanced chemiluminescence detection kit (Sigma-Aldrich; Merck KGaA). Protein results were analyzed using Image_Lab_3.0 (Bio-Rad Laboratories, Inc.).

Lactate dehydrogenase (LDH) activity and caspase-3/9 activity levels. LDH activity levels at $48 \mathrm{~h}$ post-transfection were measured using an LDH activity kit (cat. no. C0017; Beyotime Institute of Biotechnology) according to the manufacturer's protocol, and OD was measured at $450 \mathrm{~nm}$ using a microplate reader (AD-340; Beckman Coulter, Inc.).

Caspase-3/9 activity levels at $48 \mathrm{~h}$ post-transfection were assessed using caspase-3/9 activity kits (cat. nos. C1116 and C1158; Beyotime Institute of Biotechnology) according to the manufacturer's protocol, and OD was measured at $450 \mathrm{~nm}$ using a microplate reader (AD-340; Beckman Coulter, Inc.).
In vivo model. A total of 12 nude male mice (aged 5-6 weeks and weighing 17-19 g) were collected from the Animal Laboratory of Shandong University. All mice were housed at $23-25^{\circ} \mathrm{C}, 55-60 \%$ humidity, 12 -h light/dark cycle, and were given free access to food and water. The mice were inoculated with $200 \mu 1$ OVCAR-3 cells $\left(1 \times 10^{7}\right.$ cell/ml $)$ by subcutaneous injection in the axilla. Every 3 days, the tumor size was measured using a vernier caliper. The maximum tumor size was $\leq 1 \mathrm{~cm}^{3}$. The mice were euthanized by decapitation after being anesthetized with $50 \mathrm{mg} / \mathrm{kg}$ pentobarbital sodium [Sangon Biotech (Shanghai) Co., Ltd.] by intraperitoneal administration. All animal experiments were approved by the Ethics Committee of Weihai Municipal Hospital.

Immunofluorescence. After $48 \mathrm{~h}$ of transfection, OVCAR-3 cells were fixed with $4 \%$ paraformaldehyde at room temperature for $15 \mathrm{~min}$. OVCAR-3 cells were blocked with 5\% BSA and $0.25 \%$ Triton X-100 in PBS for $1 \mathrm{~h}$ at room temperature, and observed using an Olympus BX51 microscope (Olympus Corporation) at a magnification of $\mathrm{x} 40$.

Statistical analysis. Data are presented as the mean \pm standard deviation and experiments were performed in triplicate using SPSS 22.0 (IBM Corp.). Two-tailed Student's t-test or one-way ANOVA with Bonferroni post hoc test were used to analyze data depending on the result. $\mathrm{P}<0.05$ was considered to indicate a statistically significant difference.

\section{Results}

miRNA-199b-3p and ZEB1 expression in patients with ovarian cancer. To investigate the mechanism of ovarian cancer progression, changes in miRNA expression between normal and ovarian cancer tissues were analyzed. The results demonstrated that miRNA-199b-3p expression was reduced in patients with ovarian cancer compared with that in controls (Fig. 1A and B). Furthermore, the expression of miRNA-199b-3p in patients with stage III-IV ovarian cancer was decreased compared with that in patients with stage I-II disease (Fig. 1C). In addition, ZEB1 expression was increased in patients with ovarian cancer compared with that in controls (Fig. 1D and E). There was a negative correlation between ZEB1 and miRNA-199b-3p expression (Fig. 1F). These results demonstrated that miRNA-199b-3p may be involved in the progression of ovarian cancer.

miRNA-199b-3p and ZEB1 expression regulates $O S$ and DFS in patients with ovarian cancer. The results demonstrated that miRNA-199b-3p and ZEB1 expression regulated OS and DFS in patients with ovarian cancer. The OS and DFS in patients with ovarian cancer exhibiting high miRNA-199b-3p expression were longer compared with those exhibiting low expression (Fig. 2A and B). Furthermore, the OS and DFS in patients with ovarian cancer and low ZEB1 expression were longer compared with those exhibiting high expression (Fig. 2C and D).

miRNA-199b-3p expression regulates ovarian cancer cell proliferation and apoptosis in an in vitro model of ovarian 


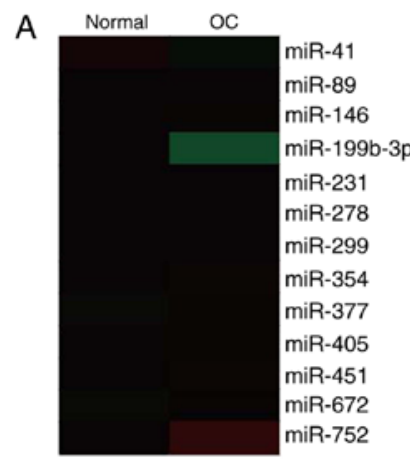

$\mathrm{B}$.
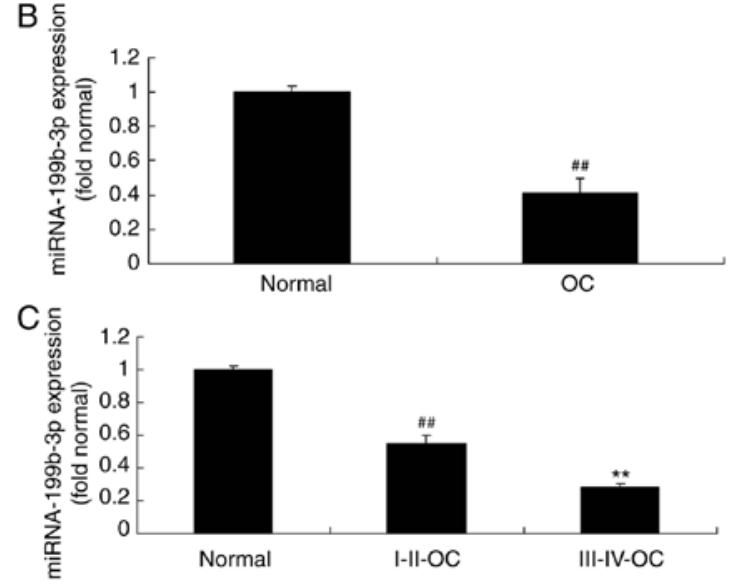
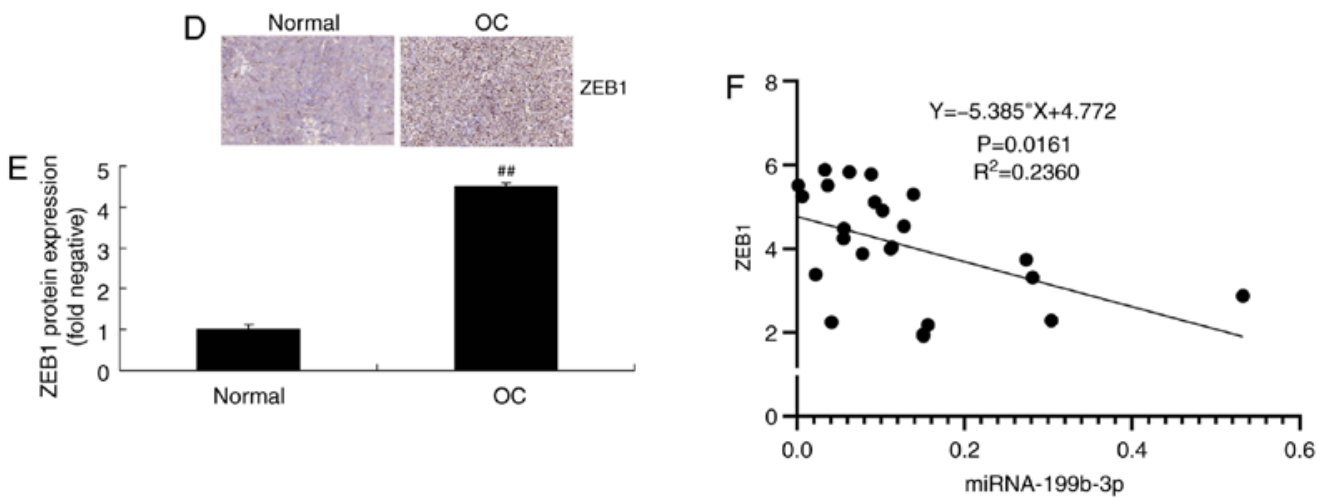

Figure 1. miRNA-199b-3p and ZEB1 expression in patients with ovarian cancer. (A) Heat map of miRNA-199b-3p expression. miRNA-199b-3p expression in (B) normal vs. OC and (C) normal vs. I-II OC and III-IV OC tissues. (D) ZEB1 expression (magnification; x100) and (E) quantification in normal vs. OC tissues. (F) Pearson's correlation test was used to analyse the correlation between ZEB1 and miRNA-199b-3p expression. ${ }^{* *} \mathrm{P}<0.01$ vs. I-II-OC, ${ }^{\# \#} \mathrm{P}<0.01$ vs. normal. miR/miRNA, microRNA; ZEB1, zinc finger E-box binding homeobox 1; OC, ovarian cancer; I-IV, stage of ovarian cancer; normal, controls.
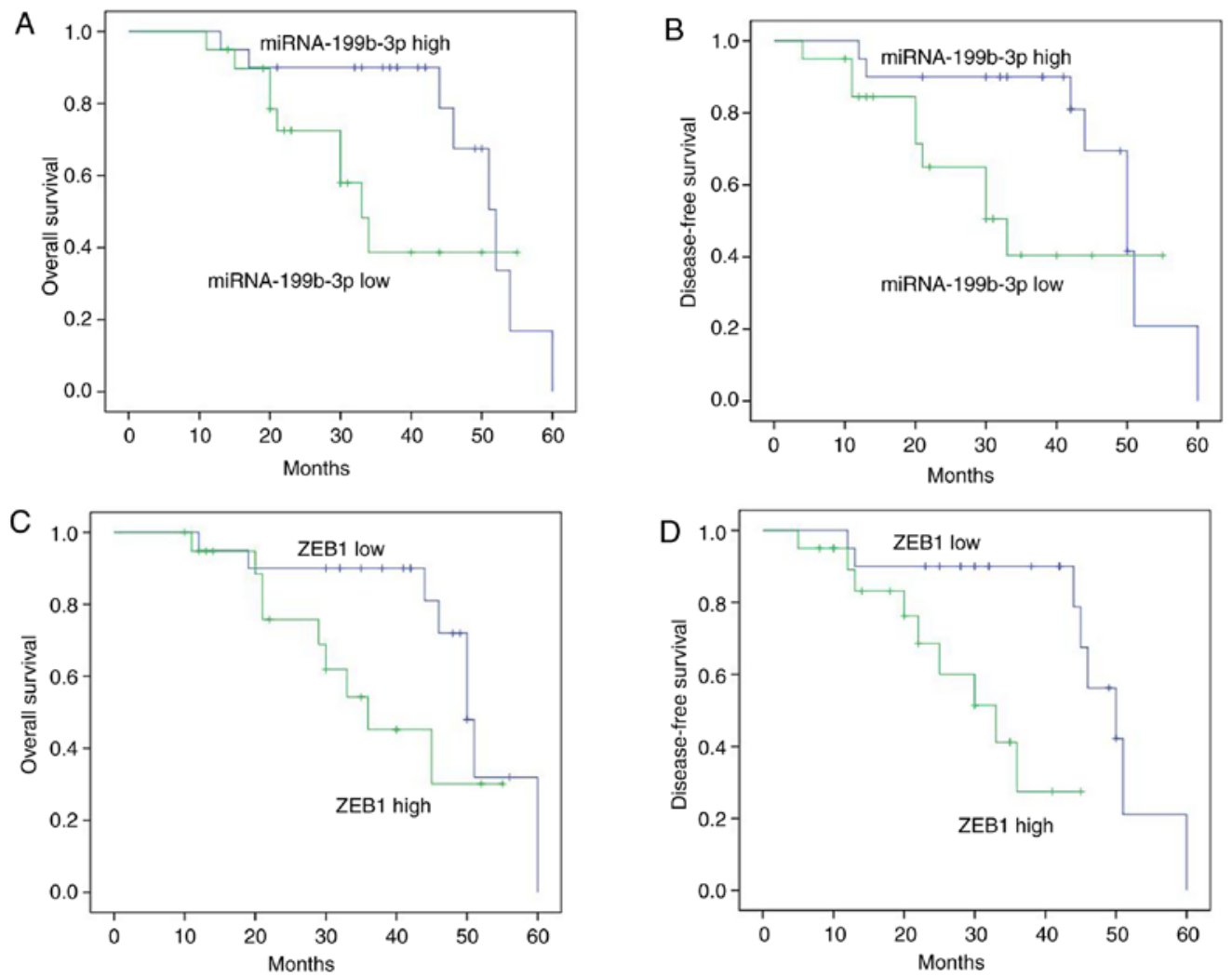

Figure 2. miRNA-199b-3p expression regulates (A) OS and (B) DFS in patients with ovarian cancer. ZEB1 expression regulates (C) OS and (D) DFS in patients with ovarian cancer. miRNA, microRNA; OS, overall survival; DFS, disease-free survival; ZEB1, zinc finger E-box binding homeobox 1. 

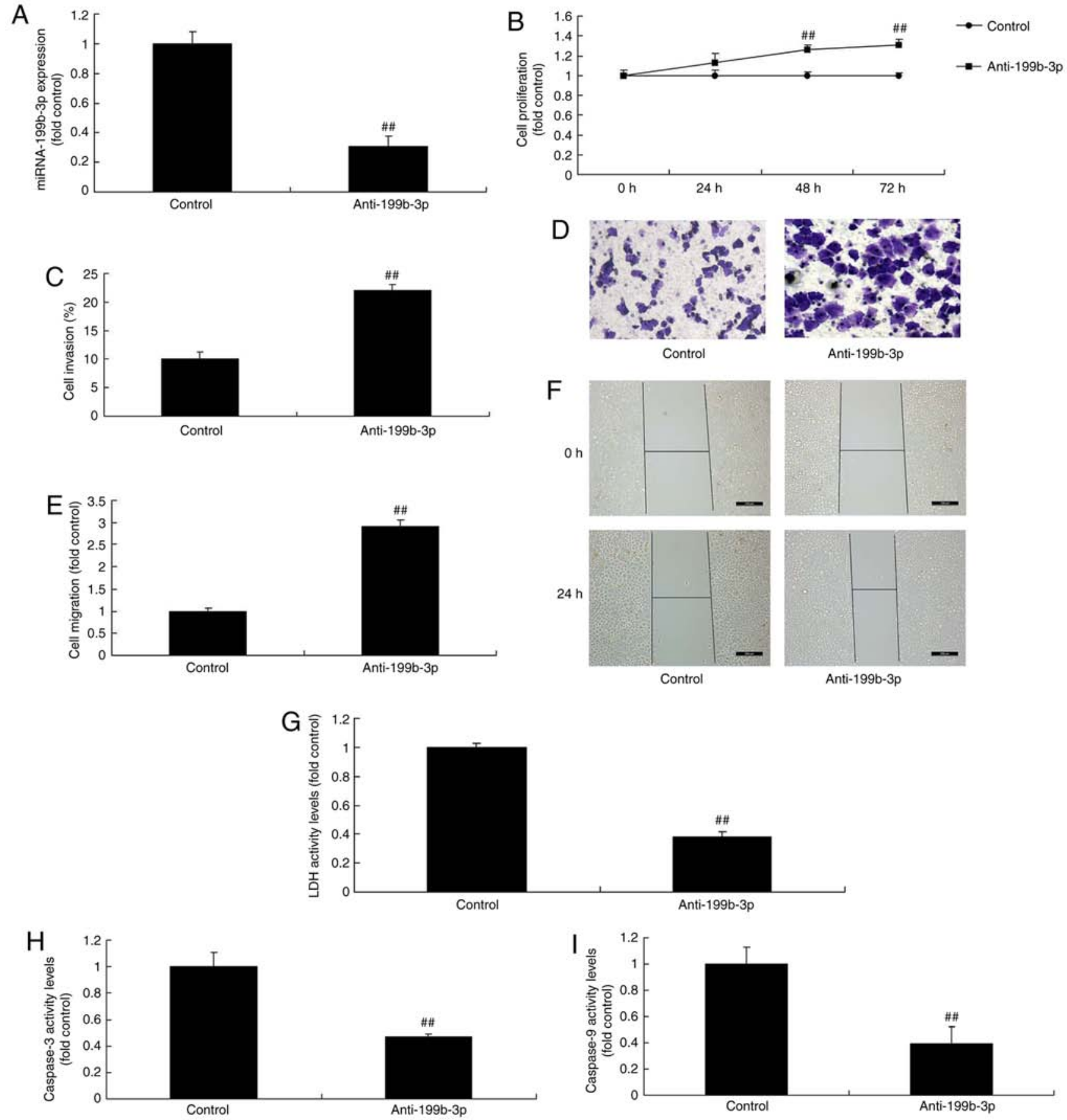

Figure 3. miRNA-199b-3p downregulation regulates cancer cell proliferation in an in vitro model of ovarian cancer. (A) miRNA-199b-3p expression. (B) Cell proliferation. Cell invasion (C) quantification and (D) staining (magnification, x20). Cell migration (E) quantification and (F) wound healing assay (magnification, x100). (G) LDH, (H) caspase-3 and (I) caspase-9 activity levels were measured. ${ }^{\# \#} \mathrm{P}<0.01$ vs. negative controls. miRNA, microRNA; LDH, lactate dehydrogenase; control, negative mimics; anti-199b-3p, downregulated miR-199b-3p. miRNA-199b-3p, overexpressed miRNA-199b-3p.

cancer. Anti-miRNA-199b-3p mimics were used to decrease miRNA-199b-3p expression in an in vitro model of ovarian cancer, and were compared with negative mimics (Fig. 3A) in order to investigate the effects of miRNA-199b-3p on ovarian cancer progression. The results demonstrated that miRNA-199b-3p inhibition increased cell proliferation, migration and invasion, and reduced LDH and caspase-3/9 activity levels compared with negative mimics (Fig. 3B-I). Furthermore, miRNA-199b-3p mimics were used to increase miRNA-199b-3p expression in an in vitro model of ovarian cancer (Fig. 4A). The results revealed that miRNA-199b-3p overexpression reduced cell proliferation, migration and invasion, and increased LDH and caspase-3/9 activity levels in an in vitro model of ovarian cancer compared with negative mimics (Fig. 4B-I). The results demonstrated that miRNA-199b-3p expression regulated ovarian cancer cell proliferation in vitro.

miRNA-199b-3p expression regulates ZEB1 in an in vitro model of ovarian cancer. To investigate the mechanism of miRNA-199b-3p in ovarian cancer progression, a gene chip was employed to analyze the signaling pathway involved in an 

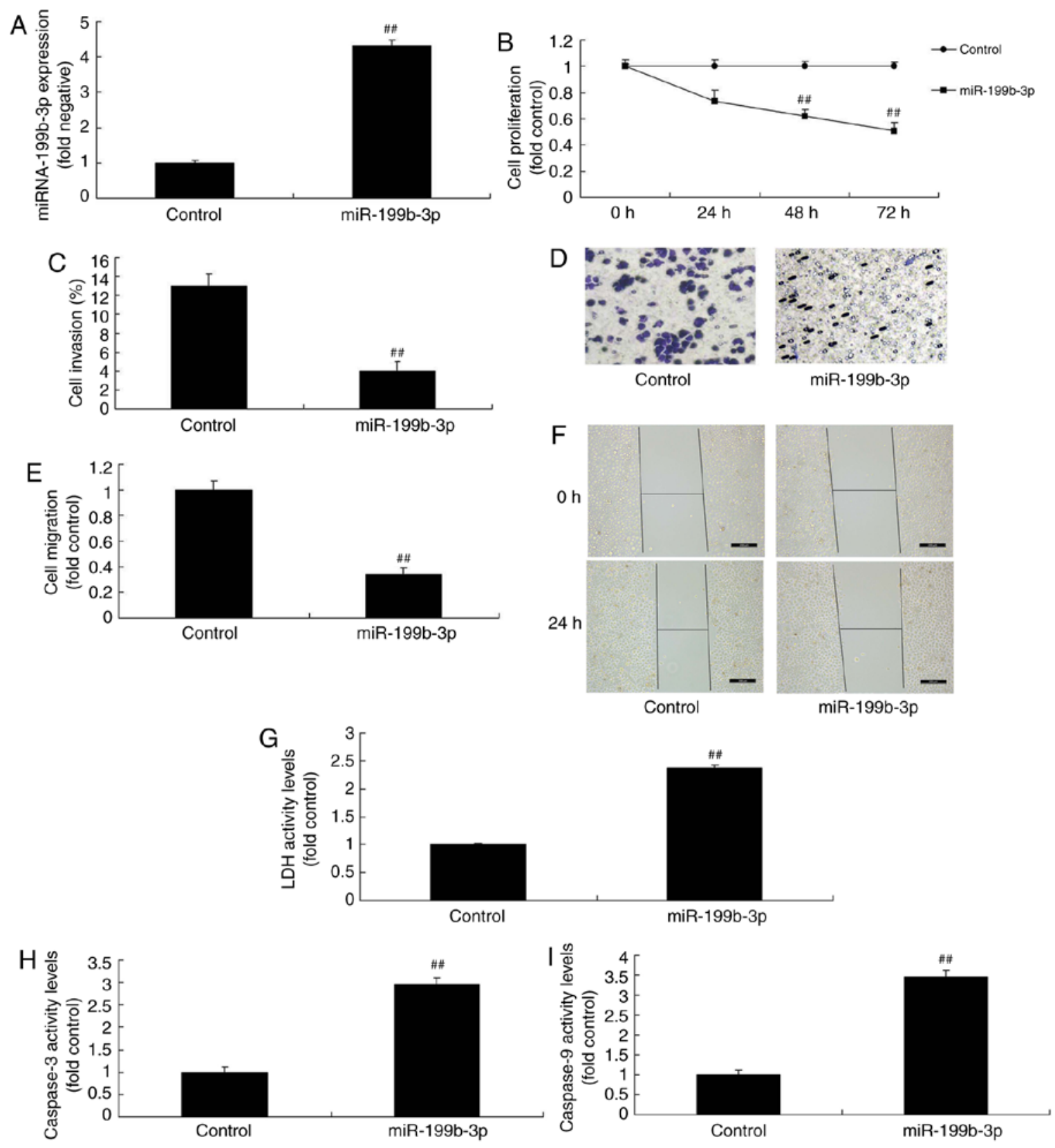

Figure 4. miRNA-199b-3p overexpression regulates cancer cell proliferation in an in vitro model of ovarian cancer. (A) miRNA-199b-3p expression. (B) Cell proliferation. Cell invasion (C) quantification and (D) staining (magnification, $\mathrm{x} 20$ ). Cell migration (E) quantification and (F) wound healing assay (magnification, x100). (G) LDH, (H) caspase-3 and (I) caspase-9 activity levels were measured. ${ }^{\# \#} \mathrm{P}<0.01$ vs. negative controls. miRNA or miR, microRNA; ZEB1, zinc finger E-box binding homeobox 1; LDH, lactate dehydrogenase; control, negative controls; miR-199b-3p, overexpressed miRNA-199b-3p.

in vitro model of ovarian cancer following miRNA-199b-3p overexpression. The results demonstrated that miRNA-199b-3p overexpression suppressed ZEB1 and CHK1 expression, and induced E-cadherin and EMT expression in an in vitro model of ovarian cancer (Fig. 5A). Furthermore, the 3'-UTR of ZEB1 was a direct target site for miRNA-199b-3p (Fig. 5B). Luciferase activity levels, ZEB1 and CHK1 expression were reduced in response to miRNA-199b-3p overexpression compared with negative controls (Fig. 5C-F and I). Additionally, E-cadherin and EMT expression were increased compared with negative controls (Fig. 5G-I). In comparison, miRNA-199b-3p downregulation induced ZEB1 and CHK1 expression and suppressed E-cadherin and EMT expression compared with negative controls (Fig. 6). These results suggested that miRNA-199b-3p expression regulated ZEB1 signaling in an in vitro model of ovarian cancer.

Anti-miRNA-199b-3p regulates ovarian cancer progression in vivo and in vitro. miRNA-199b-3p downregulation increased tumor volume in an in vivo model of ovarian cancer compared with negative controls (Fig. 7A and B). Furthermore, miRNA-199b-3p downregulation increased caspase-3/9 activity levels, induced ZEB1 and CHK1 expression and suppressed E-cadherin and EMT expression in vitro compared with negative controls (Fig. 7C-J).

ZEBI activation attenuates the effects of miRNA-199b-3p-induced apoptosis in an in vitro model of 
A

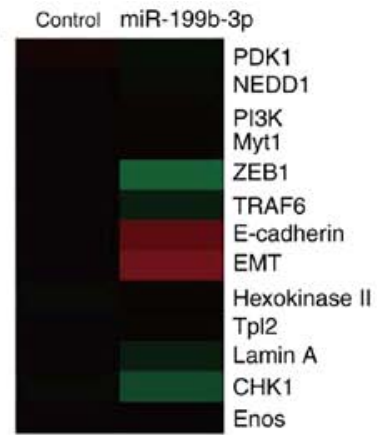

B
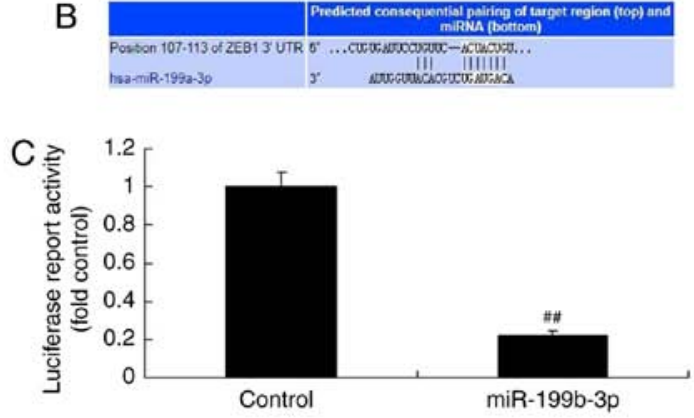

D
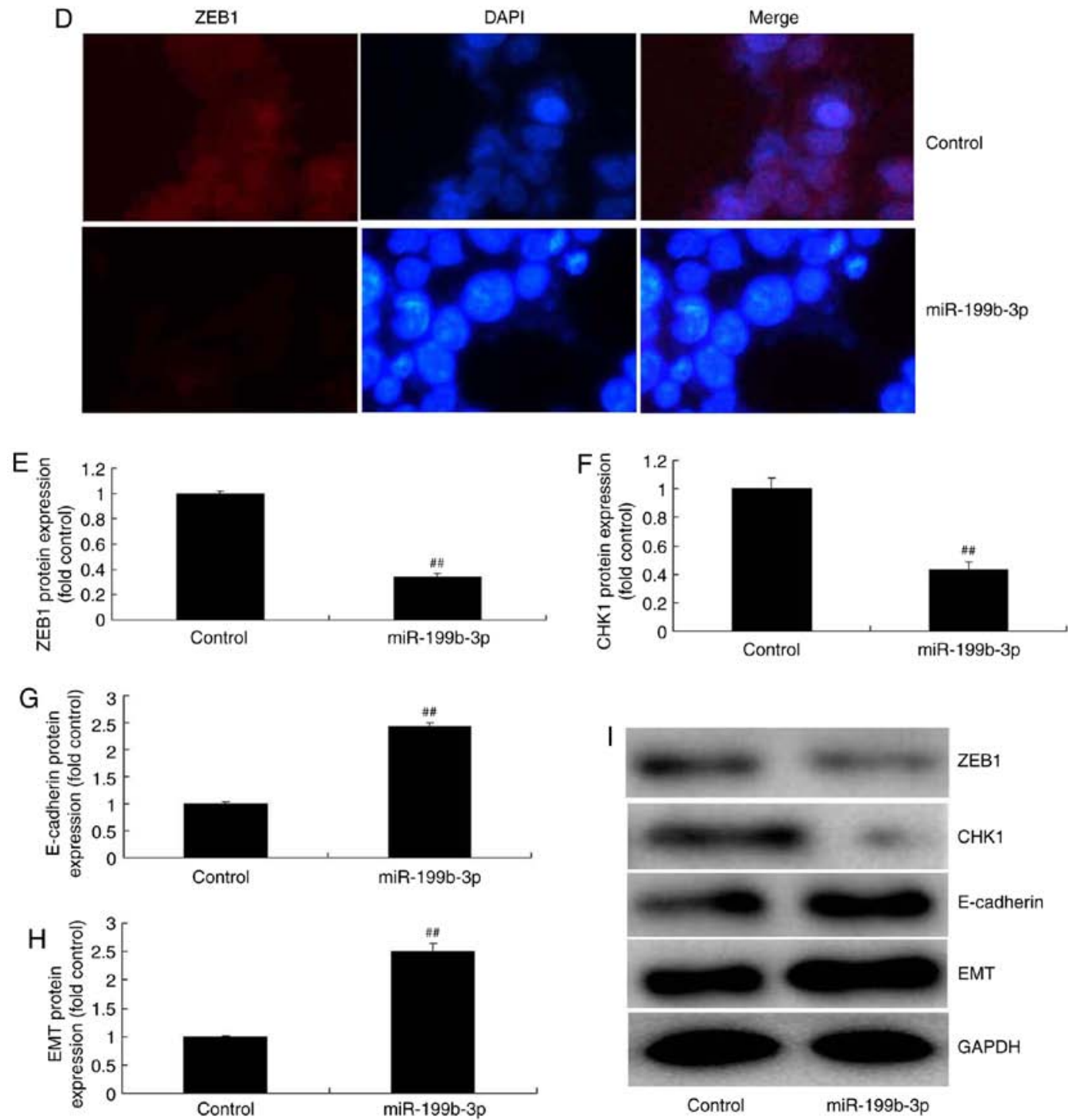

Figure 5. miRNA-199b-3p overexpression regulates ZEB1 in an in vitro model of ovarian cancer. (A) Heat map for ZEB1 signalling. (B) The 3'-UTR of ZEB1 had a direct target site for miRNA-199b-3p. (C) Luciferase activity levels. (D) Immunofluorescence for ZEB1 (magnification, $\mathrm{x} 40$ ). The protein expression of (E) ZEB1, (F) CHK1, (G) E-cadherin and (H) EMT was examined by (I) western blotting and statistical analysis. ${ }^{\# \prime} \mathrm{P}<0.01$ vs. negative controls. miRNA or miR, microRNA; ZEB1, zinc finger E-box binding homeobox 1; UTR, untranslated region; CHKI, checkpoint kinase 1; E-cadherin, epithelial cadherin; EMT, epithelial-to-mesenchymal transition; control, negative controls; miRNA-199b-3p, overexpressed miRNA-199b-3p.

ovarian cancer. pGL3-ZEB1 plasmids were used to analyze the role of ZEB1 in miRNA-199b-3p-induced apoptosis in an in vitro model of ovarian cancer. ZEB1 plasmids induced ZEB1 expression compared with negative controls (Fig. 8A). Furthermore, miRNA-199b-3p + ZEB1 transfection induced ZEB1 and CHK1 expression and suppressed E-cadherin and EMT expression in ovarian cancer cells following compared with the miRNA-199b-3p overexpression group (Fig. 8B-F). Additionally, miRNA-199b-3p + ZEB1 transfection reduced cell proliferation, migration and cell invasion, and inhibited the LDH and caspase-3/9 activity levels, compared with the miRNA-199b-3p overexpression group in an in vitro model of ovarian cancer (Fig. 9A-H). 


\section{A}
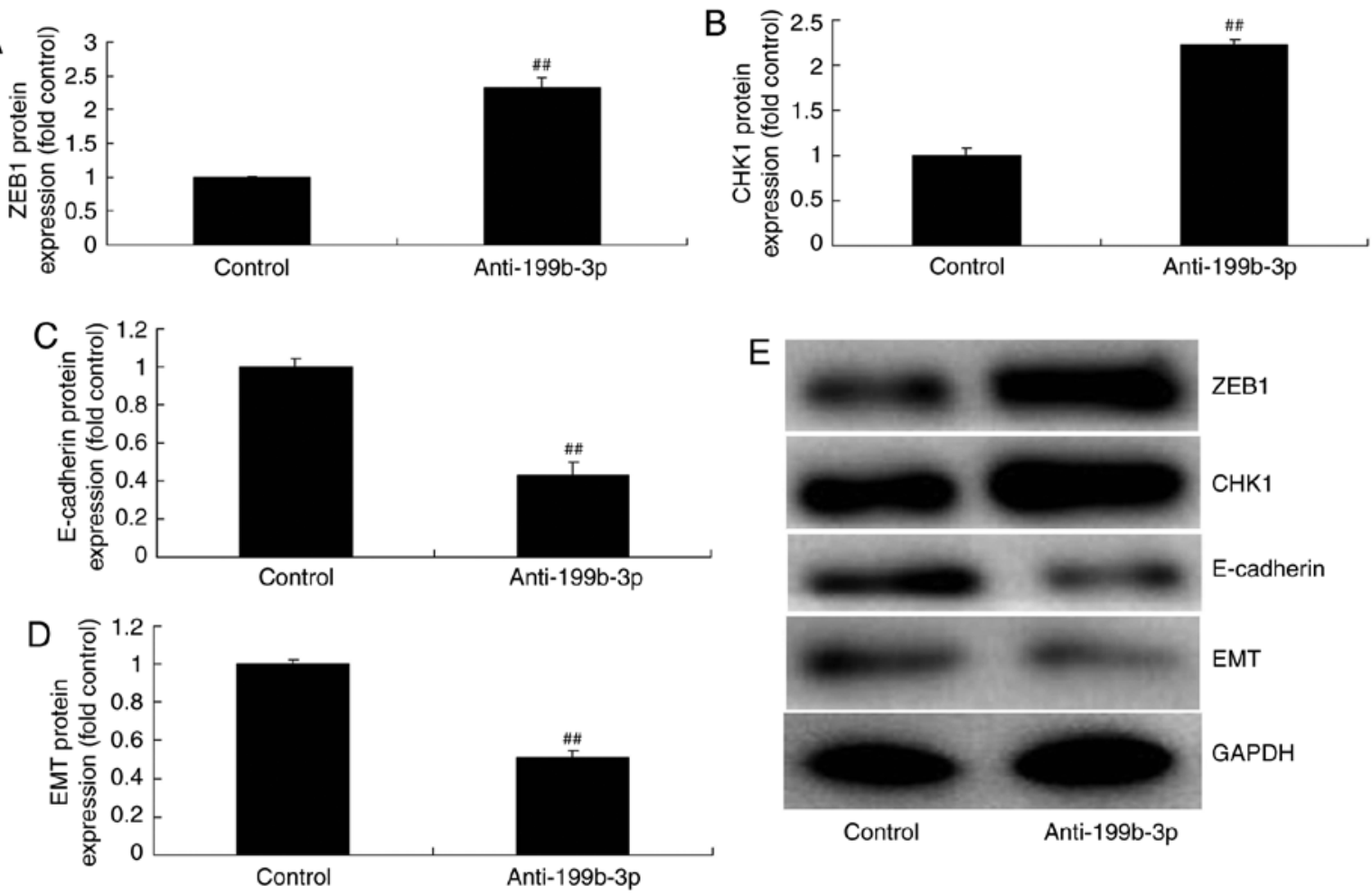

Figure 6. miRNA-199b-3p downregulation regulated ZEB1 signalling in an in vitro model of ovarian cancer. The protein expression of (A) ZEB1, (B) CHK1, (C) E-cadherin and (D) EMT was examined by (E) western blotting and statistical analysis. ${ }^{\# \#} \mathrm{P}<0.01$ vs. negative controls. miRNA, microRNA; ZEB1, zinc finger E-box binding homeobox 1; p-ZEB1, phosphorylated ZEB1; CHKI, checkpoint kinase 1; E-cadherin, epithelial cadherin; EMT, epithelial-to-mesenchymal transition; control, negative controls; anti-199b-3p, downregulated miRNA-199b-3p.

E-cadherin induction attenuates the effects of anti-miRNA-199b-3p-induced metastasis in an in vitro model of ovarian cancer. The function of E-cadherin on the effects of anti-miRNA-199b-3p-induced metastasis in an in vitro model of ovarian cancer were analyzed. E-cadherin plasmids were used to induce E-cadherin mRNA expression, which was increased compared with the negative controls (Fig. 10A). miRNA-199b-3p + E-cadherin transfection induced E-cadherin and EMT expression in ovarian cancer cells compared with downregulated miRNA-199b-3p (Fig. 10B-D). Furthermore, anti-miRNA-199b-3p + E-cadherin transfection also attenuated the effects of anti-miRNA-199b-3p on cell growth, migration and apoptosis in ovarian cancer compared with the anti-miRNA-199b-3p alone group (Fig. 10E-J). These results demonstrated that miRNA-199b-3p suppresses ovarian cancer progression via the $\mathrm{CHK} 1 / \mathrm{E}$-cadherin/EMT pathway by targeting the ZEB1 gene (Fig. 11), which may represent a potential target for ovarian cancer treatment.

\section{Discussion}

Ovarian cancer is among the major malignant tumors affecting the female reproductive system (2). The 5-year survival rate of patients with ovarian cancer is $<30 \%$ (2). Ovarian cancer has become a leading tumor that severely threatens the health and life of women globally (14). Furthermore, its onset is insidious and is difficult to detect (14). Therefore, diagnosis is often made at a clinically advanced stage after metastasis has already developed (15), making complete surgical resection challenging and postoperative recurrence frequent. As a result, ovarian cancer is considered as one of the most malignant gynecological tumors with a poor prognosis (15). Zheng et al (11) reported that miR-199b-5p inhibits triple-negative breast cancer cell proliferation, migration and invasion. In the present study, miRNA-199b-3p expression was found to be reduced in patients with ovarian cancer.

miRNAs are endogenous non-coding small RNAs that degrade target mRNAs to suppress target gene expression at the post-transcriptional level, and participate in the regulation of cell growth, proliferation and apoptosis (16). Certain miRNAs regulate the expression of various oncogenes and tumor suppressor genes, and participate in the pathogenesis, invasion and metastasis of ovarian cancer (16). Furthermore, the differential expression of certain miRNAs is closely associated with ovarian cancer resistance and prognosis $(16,17)$. Research into the target genes of ovarian cancer-related miRNAs and their signaling pathways may help design novel strategies for improving the clinical diagnosis and treatment of ovarian cancer.

Epithelial ovarian cancer cells are often subjected to hypoxia during their rapid growth process (18). Hypoxia increases the expression of the EMT-related transcription factor ZEB1 in the SKOV3 and ES-2 ovarian cancer cell lines (18). Additionally, ZEB1 reduces semaphorin 3F and activates the hypoxia-inducing factor- $1 \alpha$ in the oxygen reaction pathway (19). Furthermore, ZEB1 induces the formation of classical blood vessels as well as vasculogenic mimicry. $\mathrm{Xu}$ et al (20) reported that miR-199b-5p acts as a tumor promoter in cervical cancer. In the present study, patients 

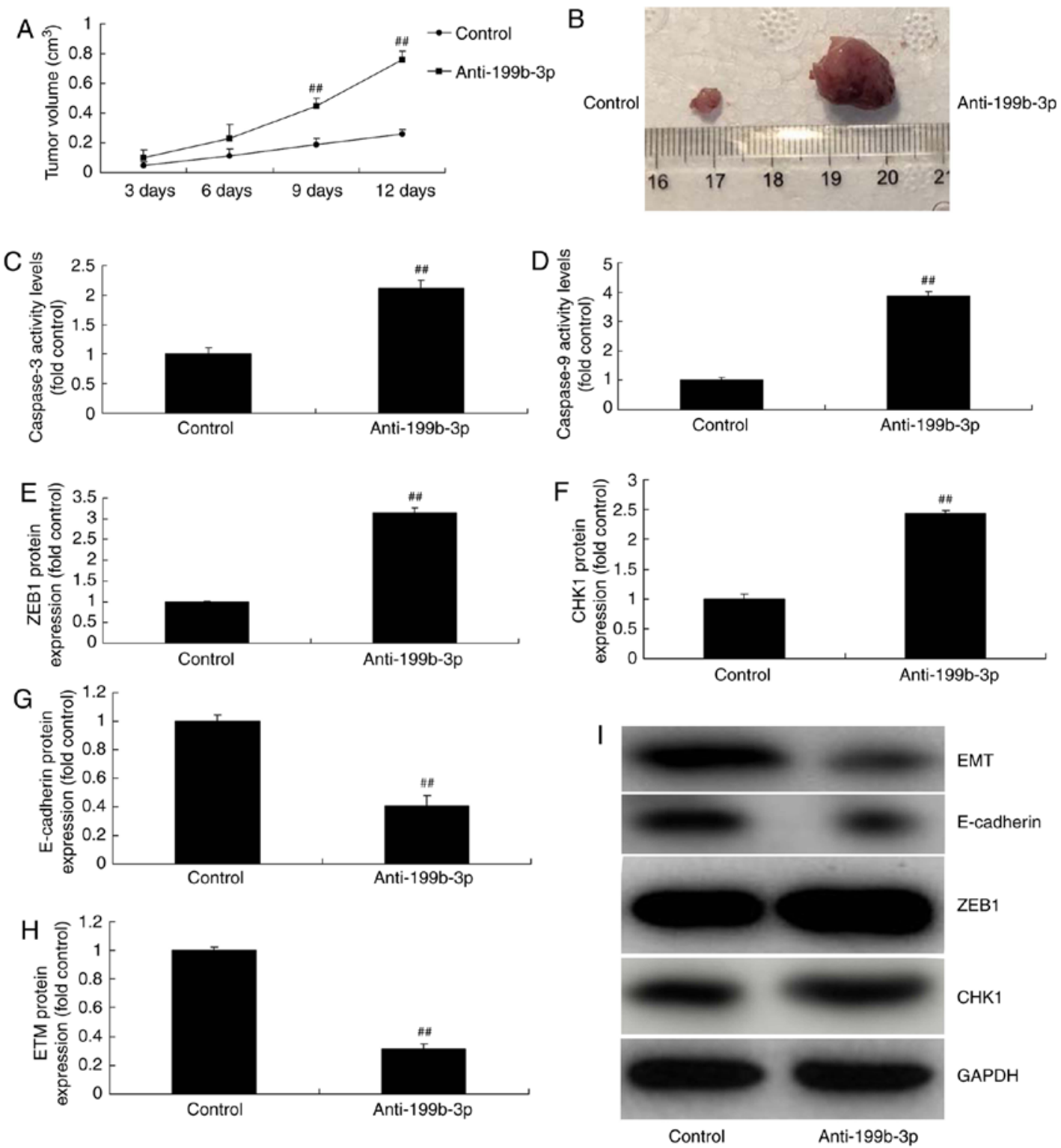

Figure 7. Anti-199b-3p regulates ovarian cancer progression in in vivo and in vitro models of ovarian cancer. Tumor (A) volume and (B) macroscopic size. (C) Caspase-3 and (D) caspase-9 activity levels. The protein expression of (E) ZEB1, (F) CHK1, (G) E-cadherin and (H) EMT were analyzed by (I) western blotting and statistical analysis. ${ }^{\# /} \mathrm{P}<0.01$ vs. negative controls. Anti-199b-3p, negative controls; ZEB1, zinc finger E-box binding homeobox 1; p-ZEB1, phosphorylated ZEB1; CHKI, checkpoint kinase 1; E-cadherin, epithelial cadherin; EMT, epithelial-to-mesenchymal transition; control, negative controls; anti-199b-3p, downregulated miRNA-199b-3p.

with ovarian cancer and high miRNA-199b-3p expression exhibited longer OS and DFS compared with patients with low expression, indicating the cancer-suppressive role of miRNA-199b-3p.

EMT plays a key role in embryogenesis, chronic inflammation, tissue reconstruction, cancer metastasis and fibrosis in multiple organs (9). Furthermore, EMT is a key biological process through which epithelium-derived malignant tumor cells can acquire the capacity to migrate and invade (21). Additionally, E-cadherin downregulation is an important event in the initial stages of EMT (22). Transcription factors that suppress E-cadherin expression are defined as EMT-inducing factors (22). In the present study, miRNA-199b-3p overexpression suppressed ZEB1 and CHK1 expression and induced E-cadherin expression and EMT in an in vitro model of ovarian cancer. Furthermore, ZEB1 activation reduced the effects of miRNA-199b-3p-mediated apoptosis in an in vitro model of ovarian cancer.

E-cadherin is a member of the cadherin family, which comprises $\mathrm{CA}^{2+}$-dependent transmembrane proteins (23). E-cadherin is the main member of the cadherin family that is universally conserved in epithelial cells and is a well-known epithelial cell biomarker (23). The abnormal expression of E-cadherin is the foundation of dissociation of cell-cell adhesion, which is closely associated with tumor invasion and metastasis (24). E-cadherin is rarely expressed in normal ovarian epithelial cells (24). However, E-cadherin expression is markedly upregulated in $85 \%$ of primary ovarian tumors. These data indicate that E-cadherin induction also reduces the effects of anti-miRNA-199b-3p-mediated metastasis in an in vitro model of ovarian cancer. Portune et al (25) demonstrated that miR-199b attenuated TGF- $\beta 1$-induced EMT/E-cadherin in 

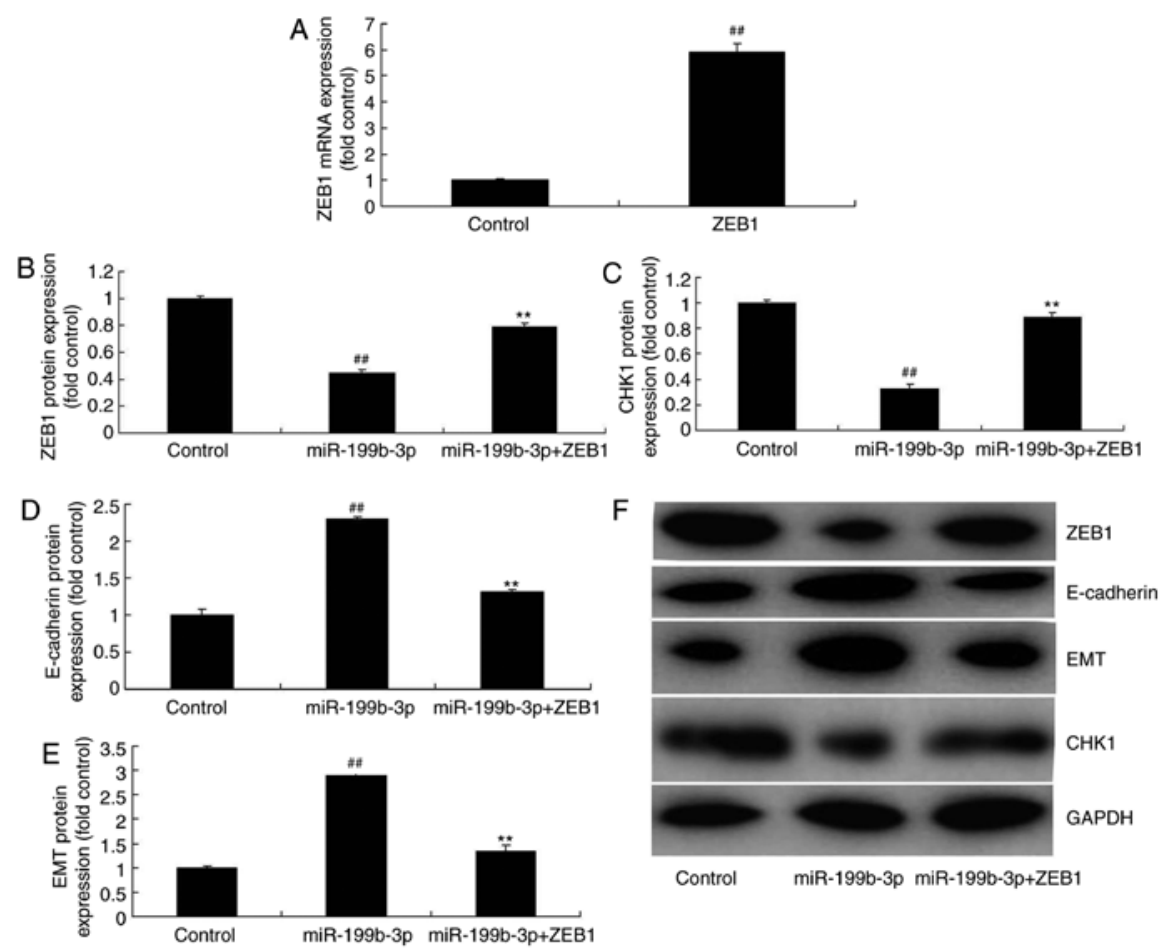

Figure 8. ZEB1 activation reduced the effects of miRNA-199b-3p on cell apoptosis in an in vitro model of ovarian cancer. (A) mRNA expression of ZEB1. The protein expression of (B) ZEB1, (C) CHK1, (D) E-cadherin and (E) EMT was examined by (F) western blotting and statistical analysis. ${ }^{\# \#<0.01 ~ v s . ~ n e g a t i v e ~}$ control group. ${ }^{* *} \mathrm{P}<0.01$ vs. overexpressed miRNA-199b-3p. ZEB1, zinc finger E-box binding homeobox 1; miRNA/miR, microRNA; p-ZEB1, phosphorylated ZEB1; CHKI, checkpoint kinase 1; E-cadherin, epithelial cadherin; EMT, epithelial-to-mesenchymal transition; control, negative controls; miR-199b-3p, overexpressed miR-199b-3p; miR-199b-3p + ZEB1; miR-199b-3p/ZEB1 transfection.
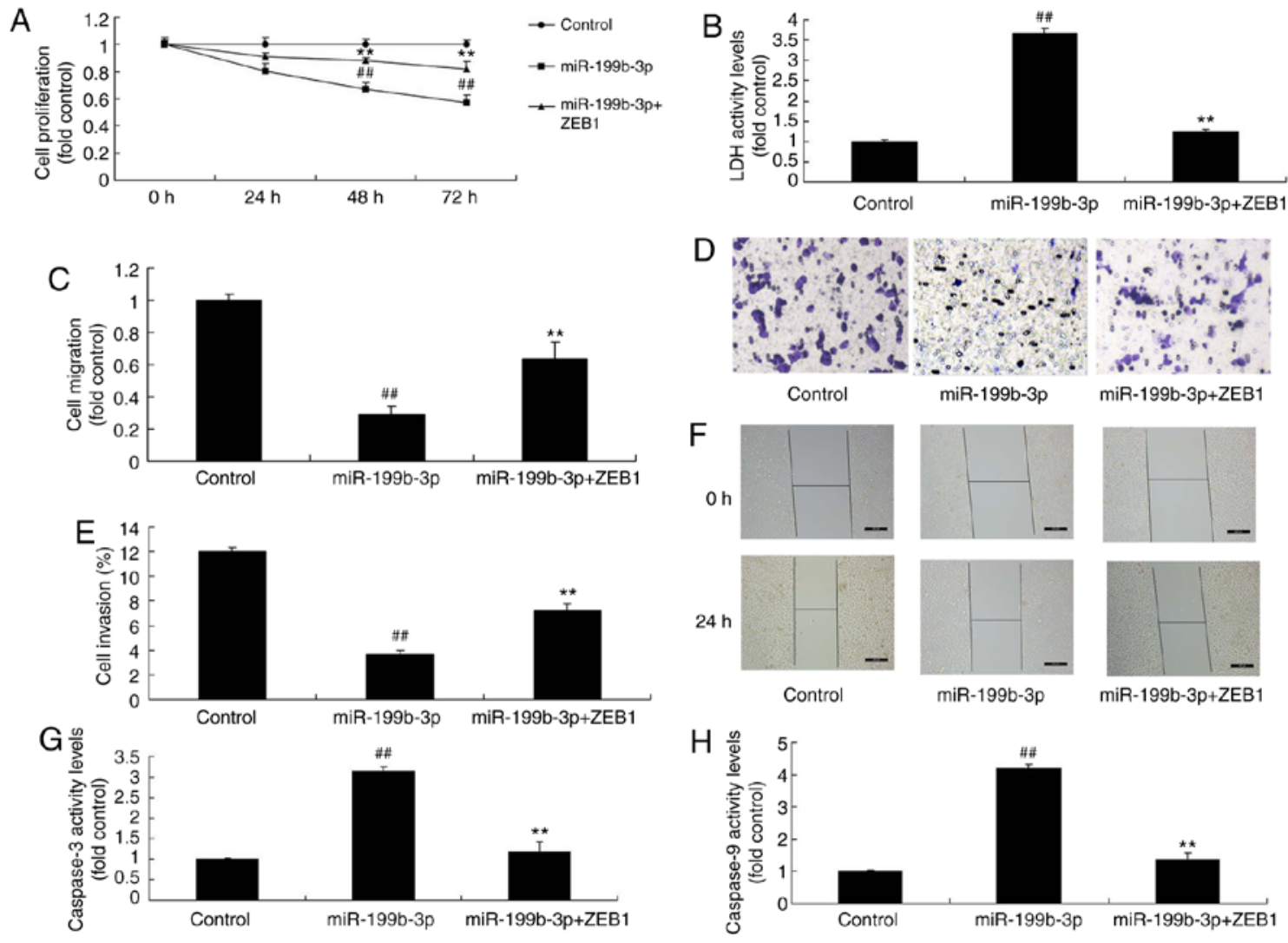

Figure 9.ZEB1 activation reduced the effects of miRNA-199b-3p on cell apoptosis in an in vitro model of ovarian cancer. (A) Cell proliferation. (B) LDH activity levels. Cell migration (C) quantification and (D) staining (magnification, x20). Cell invasion (E) quantification and (F) wound healing assay. (G) Caspase-3 and (H) caspase-9 activity levels. ${ }^{\# \#} \mathrm{P}<0.01$ vs. negative controls; ${ }^{* *} \mathrm{P}<0.01$ vs. overexpressed miRNA-199b-3p. ZEB1, zinc finger E-box binding homeobox 1 ; miRNA, microRNA; LDH, lactate dehydrogenase; control, negative controls; miR-199b-3p, overexpressed miRNA-199b-3p; miR-199b-3p + ZEB1, miR-199b-3p/ZEB1 transfection. 
A

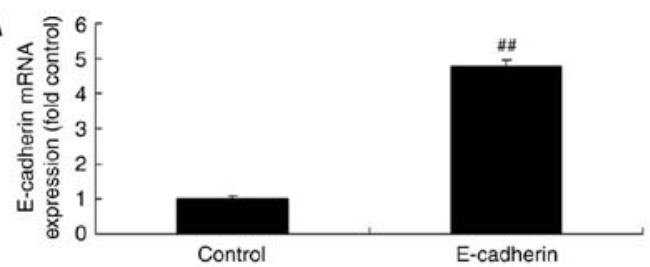

C

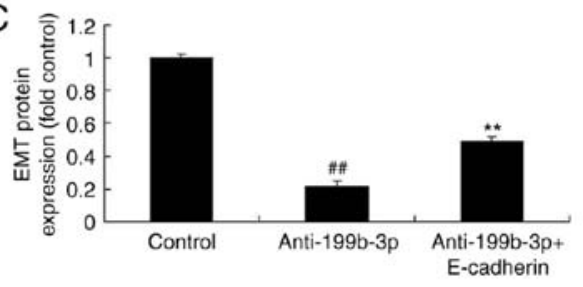

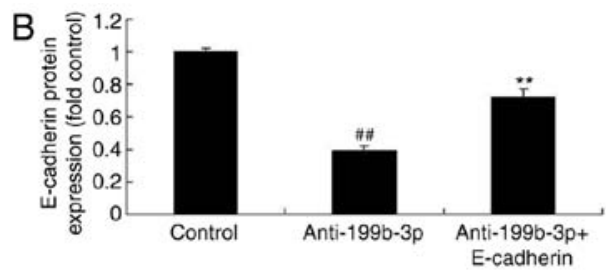

D

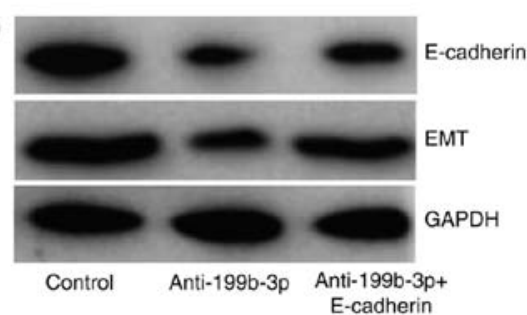

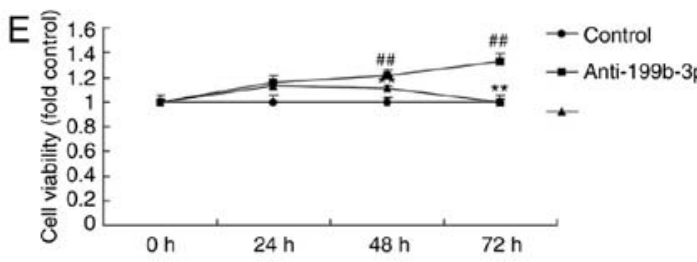
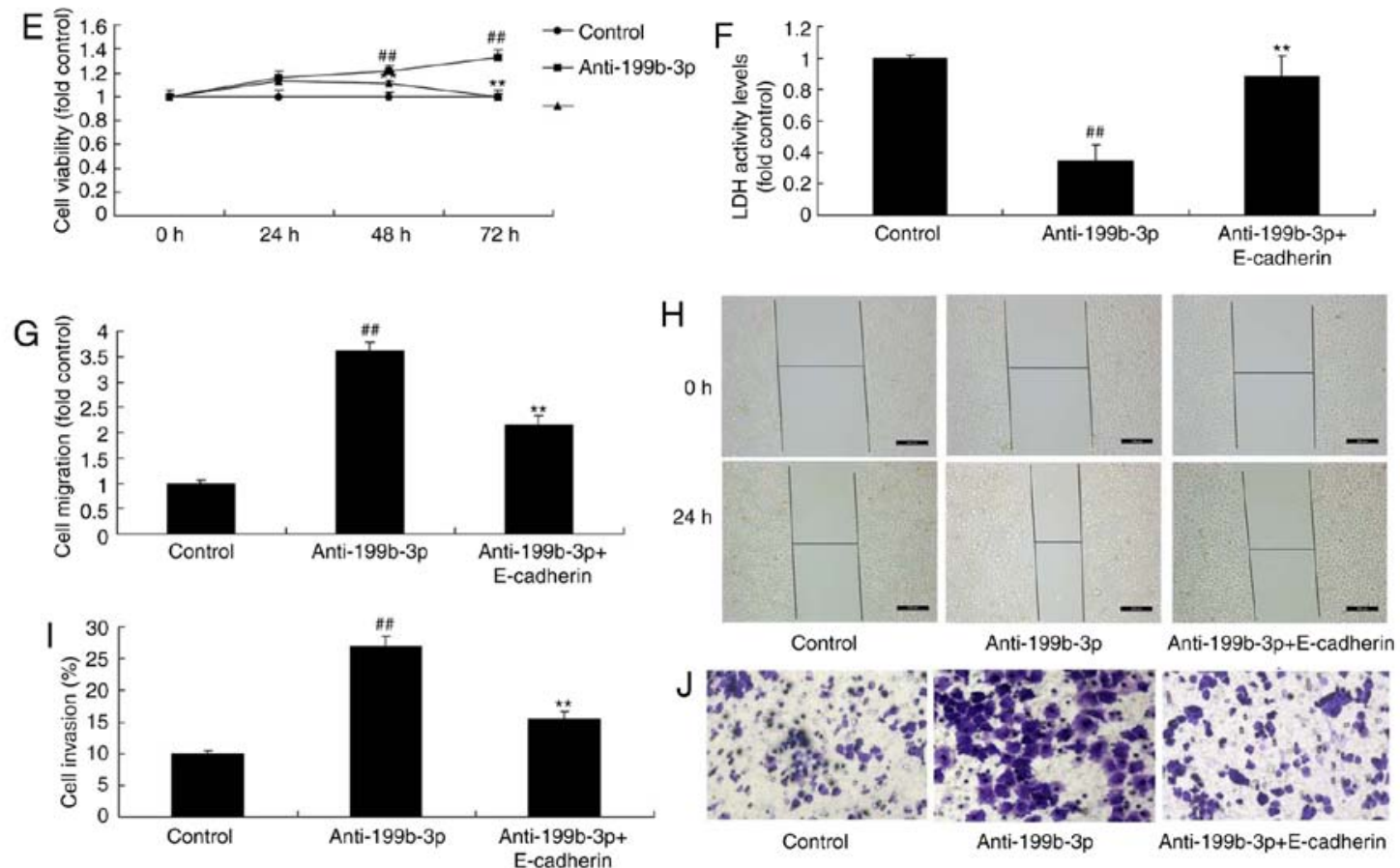

Figure 10. E-cadherin induction reduced the effects of anti-miRNA-199b-3p-induced metastasis in an in vitro model of ovarian cancer. (A) mRNA expression of E-cadherin. The protein expression of (B) E-cadherin and (C) EMT was examined by (D) western blotting and statistical analysis. (E) Cell viability. (F) LDH activity levels. Cell migration (G) quantification and (H) staining (magnification, x20). Cell invasion (I) quantification and (J) wound healing assay (magnification, x100). ${ }^{\# \#} \mathrm{P}<0.01$ vs. negative controls; ${ }^{* *} \mathrm{P}<0.01$ vs. downregulated miRNA-199b-3p. E-cadherin, epithelial cadherin; EMT, endothelial-to-mesenchymal transition; LDH, lactate dehydrogenase; miRNA, microRNA; control, negative controls; anti-199b-3p, downregulated miRNA-199b-3p; anti-199b-3p, downregulated miRNA-199b-3p; anti-199b-3p + E-cadherin, E-cadherin/anti-199b-3p transfection.

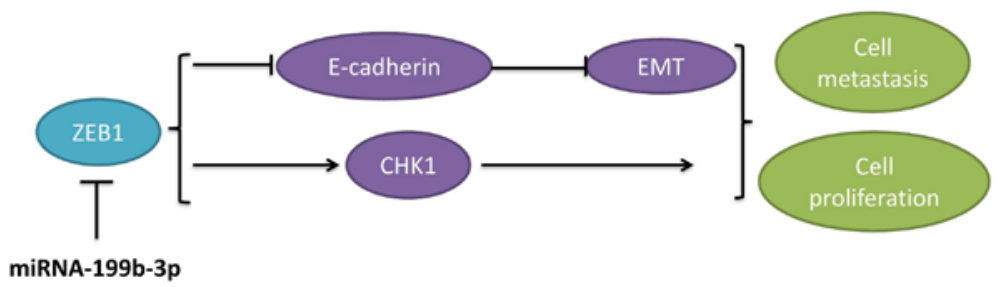

Figure 11. miRNA-199b-3p suppresses ovarian cancer cell proliferation and invasion via the CHK1/E-cadherin/EMT pathway by targeting the ZEB1 gene. CHKI, checkpoint kinase 1; E-cadherin, epithelial cadherin; EMT, epithelial-to-mesenchymal transition; ZEB1, zinc finger E-box binding homeobox 1; miRNA, microRNA.

diabetic nephropathy. The results of the present study revealed that the miRNA-199b-3p/E-cadherin/EMT pathway regulates ovarian cancer cell growth and apoptosis.
In conclusion, it was herein demonstrated that miRNA-199b-3p suppresses ovarian cancer progression via the CHK1/E-cadherin/EMT pathway by targeting the ZEB1 
gene, which may represent a potential target for ovarian cancer treatment, and that miRNA-199b-3p may be of value as a target for the treatment of ovarian cancer.

\section{Acknowledgements}

Not applicable.

\section{Funding}

The present study was supported by the Project of Medical and Health Technology Development program in Shandong province (grant no. 2017WSA10016).

\section{Availability of data and materials}

The data sets generated and analyzed during the present study are available from the corresponding author on reasonable request.

\section{Authors' contributions}

SZ designed the experiments. LW and $\mathrm{YH}$ performed the experiments. SZ, YH, SB, XL and JZ analyzed the data and $\mathrm{SZ}$ wrote the manuscript.

\section{Ethics approval and consent to participate}

The current study protocol was approved by the Medical Ethics Committee of Weihai Municipal Hospital. Informed written consent was obtained from all participants. All animal experiments were approved by the Ethics Committee of Weihai Municipal Hospital.

\section{Patient consent for publication}

Not applicable.

\section{Competing interests}

The authors declare that they have no competing interests.

\section{References}

1. Gray HJ, Bell-McGuinn K, Fleming GF, Cristea M, Xiong H, Sullivan D, Luo Y, McKee MD, Munasinghe W and Martin LP Phase I combination study of the PARP inhibitor veliparib plus carboplatin and gemcitabine in patients with advanced ovarian cancer and other solid malignancies. Gynecol Oncol 148 507-514, 2018.

2. Fu X, Zhang Y, Wang X, Chen M, Wang Y, Nie J, Meng Y and Han W: Low dose decitabine combined with taxol and platinum chemotherapy to treat refractory/recurrent ovarian cancer: An open-label, single-arm, phase I/II study. Curr Protein Pept Sci 16: 329-336, 2015.

3. Liu GL, Yang HJ, Liu B and Liu T: Effects of microRNA-19b on the proliferation, apoptosis, and migration of Wilms' tumor cells via the PTEN/PI3K/AKT signaling pathway. J Cell Biochem 118: 3424-3434, 2017.

4. Gao J, Wu N, Liu X, Xia Y, Chen Y, Li S and Deng Z: MicroRNA-142-3p inhibits cell proliferation and chemoresistance in ovarian cancer via targeting sirtuin 1. Exp Ther Med 15: 5205-5214, 2018
5. Liang H, Zhao X, Wang C, Sun J, Chen Y, Wang G, Fang L, Yang R, Yu M, Gu Y and Shan H: Systematic analyses reveal long non-coding RNA (PTAF)-mediated promotion of EMT and invasion-metastasis in serous ovarian cancer. Mol Cancer 17: 96, 2018.

6. Wu DI, Liu L, Ren C, Kong D, Zhang P, Jin X, Wang T and Zhang G: Epithelial-mesenchymal interconversions and the regulatory function of the ZEB family during the development and progression of ovarian cancer. Oncol Lett 11: 1463-1468, 2016.

7. Sadlecki P, Jóźwicki J, Antosik P and Grabiec M: Expression of selected epithelial-mesenchymal transition transcription factors in serous borderline ovarian tumors and type I ovarian cancers. Tumour Biol 40: 1010428318784807, 2018.

8. Mitra T, Prasad P, Mukherjee P, Chaudhuri SR and Chatterji U: Stemness and chemoresistance are imparted to the OC cells through TGF $\beta 1$ driven EMT. J Cell Biochem 119: 5775-5787, 2018.

9. Leng R, Liao G, Wang H, Kuang J and Tang L: Racl expression in epithelial ovarian cancer: Effect on cell EMT and clinical outcome. Med Oncol 32: 329, 2015.

10. Weingarten C, Jenudi Y, Tshuva RY, Moskovich D, Alfandari A, Hercbergs A, Davis PJ, Ellis M and Ashur-Fabian O: The interplay between epithelial-mesenchymal transition (EMT) and the thyroid hormones- $\alpha v \beta 3$ axis in ovarian cancer. Horm Cancer 9: 22-32, 2018.

11. Zheng X, Huang F, Zhao A, Lei S, Zhang Y, Xie G, Chen T, Qu C, Rajani C, Dong B, et al: Bile acid is a significant host factor shaping the gut microbiome of diet-induced obese mice. BMC Biol 15: 120, 2017.

12. Koshizuka K, Hanazawa T, Kikkawa N, Arai T, Okato A, Kurozumi A, Kato M, Katada K, Okamoto Y and Seki N: Regulation of ITGA3 by the anti-tumor miR-199 family inhibits cancer cell migration and invasion in head and neck cancer. Cancer Sci 108: 1681-1692, 2017.

13. Blaha RZ, Arnett AB, Kirkwood MW, Taylor HG, Stancin T, Brown TM and Wade SL: Factors influencing attrition in a multisite, randomized, clinical trial following traumatic brain injury in adolescence. J Head Trauma Rehabil 30: E33-E40, 2015.

14. Rochet N, Lindel K, Katayama S, Schubert K, Herfarth K, Schneeweiss A, Sohn C, Harms W and Debus J: Intensity-modulated whole abdomen irradiation following adjuvant carboplatin/taxane chemotherapy for FIGO stage III ovarian cancer: Four-year outcomes. Strahlenther Onkol 191: $582-589,2015$.

15. Kim Y, Guntupalli SR, Lee SJ, Behbakht K, Theodorescu D, Lee JK and Diamond JR: Retrospective analysis of survival improvement by molecular biomarker-based personalized chemotherapy for recurrent ovarian cancer. PLoS One 9: e86532, 2014.

16. Záveský L, Jandáková E, Weinberger V, Minář L, Hanzíková V, Dušková D, Drábková LZ, Svobodová I and Hořínek A: Ascites-derived extracellular microRNAs as potential biomarkers for ovarian cancer. Reprod Sci 26: 510-522, 2018.

17. Loginov VI, Pronina IV, Burdennyy AM, Filippova EA, Kazubskaya TP, Kushlinsky DN, Utkin DO, Khodyrev DS, Kushlinskii NE, Dmitriev AA and Braga EA: Novel miRNA genes deregulated by aberrant methylation in ovarian carcinoma are involved in metastasis. Gene 662: 28-36, 2018.

18. Bendoraite A, Knouf EC, Garg KS, Parkin RK, Kroh EM, O'Briant KC, Ventura AP, Godwin AK, Karlan BY, Drescher CW, et al: Regulation of miR-200 family microRNAs and ZEB transcription factors in ovarian cancer: Evidence supporting a mesothelial-to-epithelial transition. Gynecol Oncol 116: 117-125, 2010

19. Yu X, Wang Y, Qiu H, Song H, Feng D, Jiang Y, Deng S, Meng H and Geng J: AEG-1 contributes to metastasis in hypoxia-related ovarian cancer by modulating the HIF-1alpha/NF-kappaB/VEGF pathway. Biomed Res Int 2018: 3145689, 2018.

20. Xu LJ, Duan Y, Wang P and Yin HQ: MiR-199b-5p promotes tumor growth and metastasis in cervical cancer by downregulating KLK10. Biochem Biophys Res Commun 503: 556-563, 2018.

21. Mao M, Zheng X, Jin B, Zhang F, Zhu L and Cui L: Effects of CD44 and E-cadherin overexpression on the proliferation, adhesion and invasion of ovarian cancer cells. Exp Ther Med 14: 5557-5563, 2017. 
22. Wang YP, Wang QY, Li CH and Li XW: COX-2 inhibition by celecoxib in epithelial ovarian cancer attenuates E-cadherin suppression through reduced Snail nuclear translocation. Chem Biol Interact 292: 24-29, 2018.

23. Huang HN, Huang WC, Lin $\mathrm{CH}$, Chiang YC, Huang $\mathrm{HY}$ and Kuo KT: Chromosome 20q13.2 ZNF217 locus amplification correlates with decreased E-cadherin expression in ovarian clear cell carcinoma with PI3K-Akt pathway alterations. Hum Pathol 45: 2318-2325, 2014.
24. Wang Y, Ma J, Shen H, Wang C, Sun Y, Howell SB and Lin X: Reactive oxygen species promote ovarian cancer progression via the HIF-1 $\alpha /$ LOX/E-cadherin pathway. Oncol Rep 32: 2150-2158, 2014

25. Portune KJ, Benítez-Páez A, Del Pulgar EM, Cerrudo V and Sanz Y: Gut microbiota, diet, and obesity-related disorders-The good, the bad, and the future challenges. Mol Nutr Food Res 61, 2017.

(i) (9) This work is licensed under a Creative Commons cc) International (CC BY-NC-ND 4.0) License. 